\title{
Verification and Validation in NASA-CUIP LOX/Methane Injector Research Efforts
}

\author{
Hugh W. Coleman \\ Propulsion Research Center \\ and \\ Department of Mechanical and Aerospace Engineering \\ University of Alabama in Huntsville \\ Huntsville, AL 35899 \\ Sibtosh Pal ${ }^{\dagger}$ \\ Propulsion Engineering Research Center \\ and \\ Department of Mechanical and Nuclear Engineering \\ The Pennsylvania State University \\ University Park, PA 16802
}

The NASA-CUIP program is supporting experimental and modeling/computational research efforts investigating wall heat flux characteristics of LOX/methane single-element injectors. A Verification and Validation (V\&V) task has begun with the objective of quantifying the degree of accuracy of the models for wall heat flux distributions at specific sets of conditions. The V\&V approach used is that being drafted as a standard by the ASME Performance Test Codes Committee, PTC 61: Verification and Validation in Computational Fluid Dynamics and Heat Transfer. The approach is based on well-established concepts from experimental uncertainty analysis. Initially the V\&V and uncertainty estimation efforts will use data obtained previously in the same facility using oxygen/hydrogen in singleelement injector testing. In this paper the V\&V process, experimental facility, and computer code are described, and approaches to estimating the associated uncertainties are discussed.

\footnotetext{
* Professor, Associate Fellow AIAA.

+ Senior Research Associate, Member AIAA.
} 


\section{Introduction}

$\mathrm{T}$ he NASA-CUIP program is supporting experimental and modeling/computational research efforts investigating wall heat flux characteristics of LOX/methane single-element injectors. This work is part of a larger effort to enable CFD codes as injector design tools ${ }^{\prime}$. CFD has shown great potential to simulate phenomena such as heat flux as a function of independent injector design variables. However, lack of demonstrated accuracy of the solutions has been identified as a major obstacle to achieving that potential (ref tucker CUIP paper). Thus, the issue of critical assessment (and improvement where necessary) of simulations and modeling for design must be addressed. Verification and validation (V\&V) are becoming recognized as the approach for quantifying and building this confidence ${ }^{2}$.

A V\&V task has begun with the objective of quantifying the degree of accuracy of the models for wall heat flux distributions at specific sets of conditions. The V\&V approach used is that being drafted as a standard by the ASME Performance Test Codes Committee, PTC 61: Verification and Validation in Computational Fluid Dynamics and Heat Transfer. The approach is based on well-established concepts from experimental uncertainty analysis, and it is discussed in Section II. The experiments are being performed in the facility at Pennsylvania State University which is described in Section III. Initially the V\&V and uncertainty estimation efforts will use data obtained previously in the same facility using oxygen/hydrogen in single-element injector testing. The simulation results will be obtained at NASA Marshall Space Flight Center using the Loci-CHEM code described in Section IV.

\section{Verification and Validation Approach}

\section{A. Basic Concepts}

Validation is the process of determining the degree to which a model is an accurate representation of the physical world. This is accomplished by comparing the simulation result (solution) with an experimental result (data) for specified validation variables at a specified set of conditions (validation point). Often a validation effort will include a number of validation points that cover a range of conditions within a domain of interest.

The V\&V approach used in this effort quantifies the degree of accuracy inferred from the comparison of solution and data for a specified variable at a specified validation point. The approach, first proposed in Ref. 3, uses the concepts from experimental uncertainty analysis ${ }^{4-6}$ to consider the errors and uncertainties in both the solution and the data.

Pertinent definitions are: $(\delta)$ error (of measurement): result of a measurement minus a true value of the measurand, and (u) uncertainty (of measurement): parameter, associated with the result of a measurement, that characterizes the dispersion of the values that could reasonably be attributed to the measurand. Also, from the 1984 first edition of Ref. 7: (u) an estimate characterizing the range of values within which the true value of a measurand lies. These concepts were extended in Ref. 3 to apply to the value of a solution variable from a simulation as well as a measured value of the variable from an experiment.

An error $\delta$ is then a quantity that has a particular sign and magnitude. In this V\&V approach, it is assumed that each error whose sign and magnitude is known has been removed by correction. Any remaining error is thus of unknown sign and magnitude, and an uncertainty $u$ is estimated with the idea that the range $\pm u$ contains the value of $\delta$ at some degree of confidence. In experimental uncertainty analysis ${ }^{4}, \mathrm{u}$ is the standard uncertainty and corresponds conceptually to an estimate of the standard deviation $\sigma$ of the parent distribution from which $\delta$ is a single realization. No assumption about the form of the parent distribution is associated with the definition of $u$.

In the conceptual and mathematical approach specified in Ref. 4, there is no distinction made between errors that are "random" and those that are "systematic." A systematic error is a single realization from some parent population of possible values from a systematic error source, and the corresponding systematic standard uncertainty $u$ is the estimate of the standard deviation $\sigma$ of that parent population. For example, the error in a solution variable caused by numerically solving the equations will be a constant once the simulation is completed. Before the simulation is run, however, the sign and magnitude of that error are undetermined until a particular grid is chosen and the simulation is run.

\section{B. Validation Approach}

In the validation process, a simulation result (solution) is compared with an experimental result (data) for specified validation variables at a specified set of conditions (validation point). As an example (Figure 1), consider 
that wall heat flux at specified chamber pressure, fuel and oxidizer flow rates, location in the combustor, ..., etc is the variable of interest.

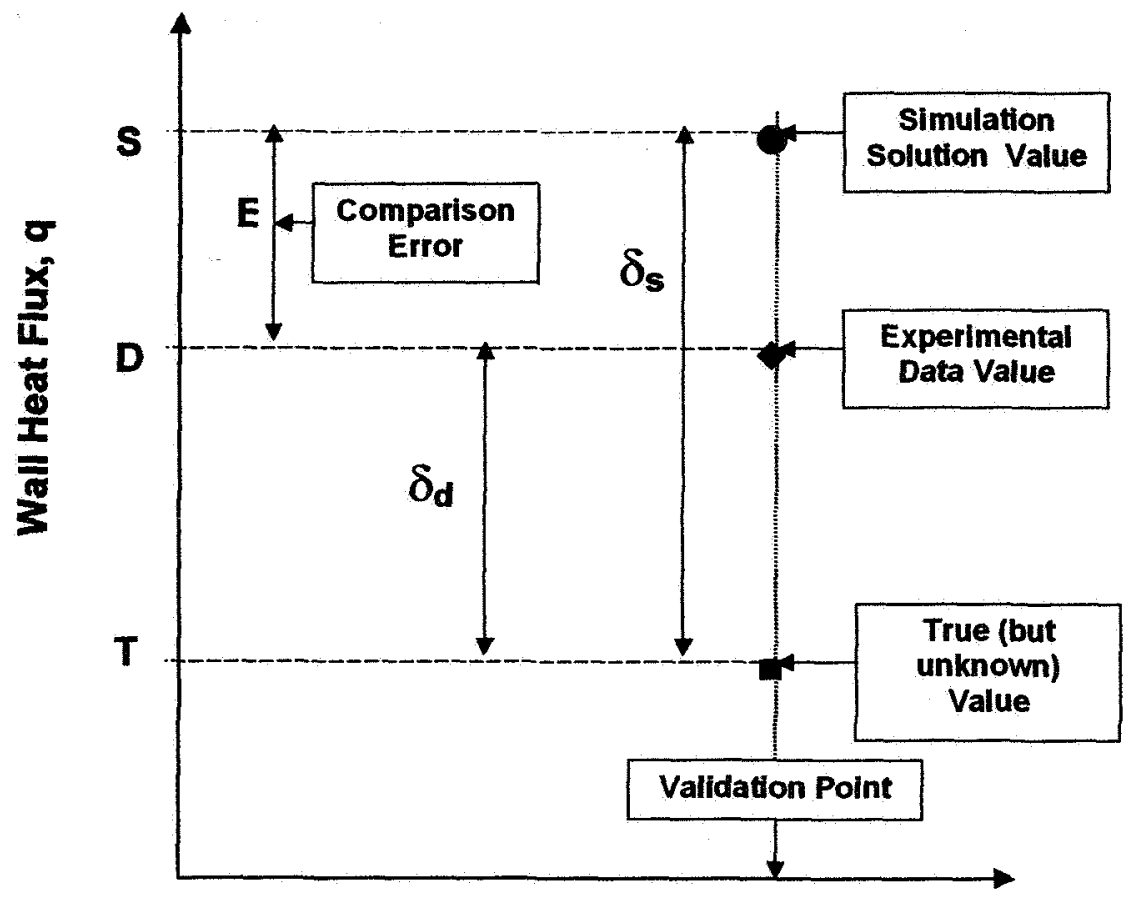

\section{Chamber Pressure}

Figure 1. Schematic showing nomenclature for validation approach.

Denote the predicted value of heat flux from the simulation solution as $S$, the value of heat flux determined from experimental data as $D$, and the true (but unknown) value of heat flux as $T$. The validation comparison error $E$ is defined as

$$
E=S-D
$$

The error in the solution value $S$ is the difference in $S$ and the true value $T$

$$
\delta_{\mathrm{S}}=\mathrm{S}-\mathrm{T}
$$

and similarly the error in the experimental value $D$ is

$$
\delta_{\mathrm{D}}=\mathrm{D}-\mathrm{T}
$$

Using Equations (1) - (3), E can be expressed as

$$
\mathrm{E}=\mathrm{S}-\mathrm{D}=\left(\mathrm{T}+\delta_{\mathrm{S}}\right)-\left(\mathrm{T}+\delta_{\mathrm{D}}\right)=\delta_{\mathrm{S}}-\delta_{\mathrm{D}}
$$

The validation comparison error $\mathrm{E}$ is thus the combination of all of the errors in the simulation result and the experimental result, and its sign and magnitude are known once the validation comparison is made.

All errors in $\mathrm{S}$ can be assigned to one of three categories ${ }^{3}$ : the error $\delta_{\text {num }}$ due to the numerical solution of the equations; the error $\delta_{\text {input }}$ in the simulation result due to errors in the simulation input parameters (material properties 
and measured boundary conditions, for example); and the error $\delta_{\text {model }}$ due to modeling assumptions and approximations. The comparison error can then be written as

$$
\mathrm{E}=\delta_{\mathrm{S}}-\delta_{\mathrm{D}}=\delta_{\text {num }}+\delta_{\text {input }}+\delta_{\text {model }}-\delta_{\mathrm{D}}
$$

This approach is shown schematically in Figure 2, where the sources of error are shown in the ovals.

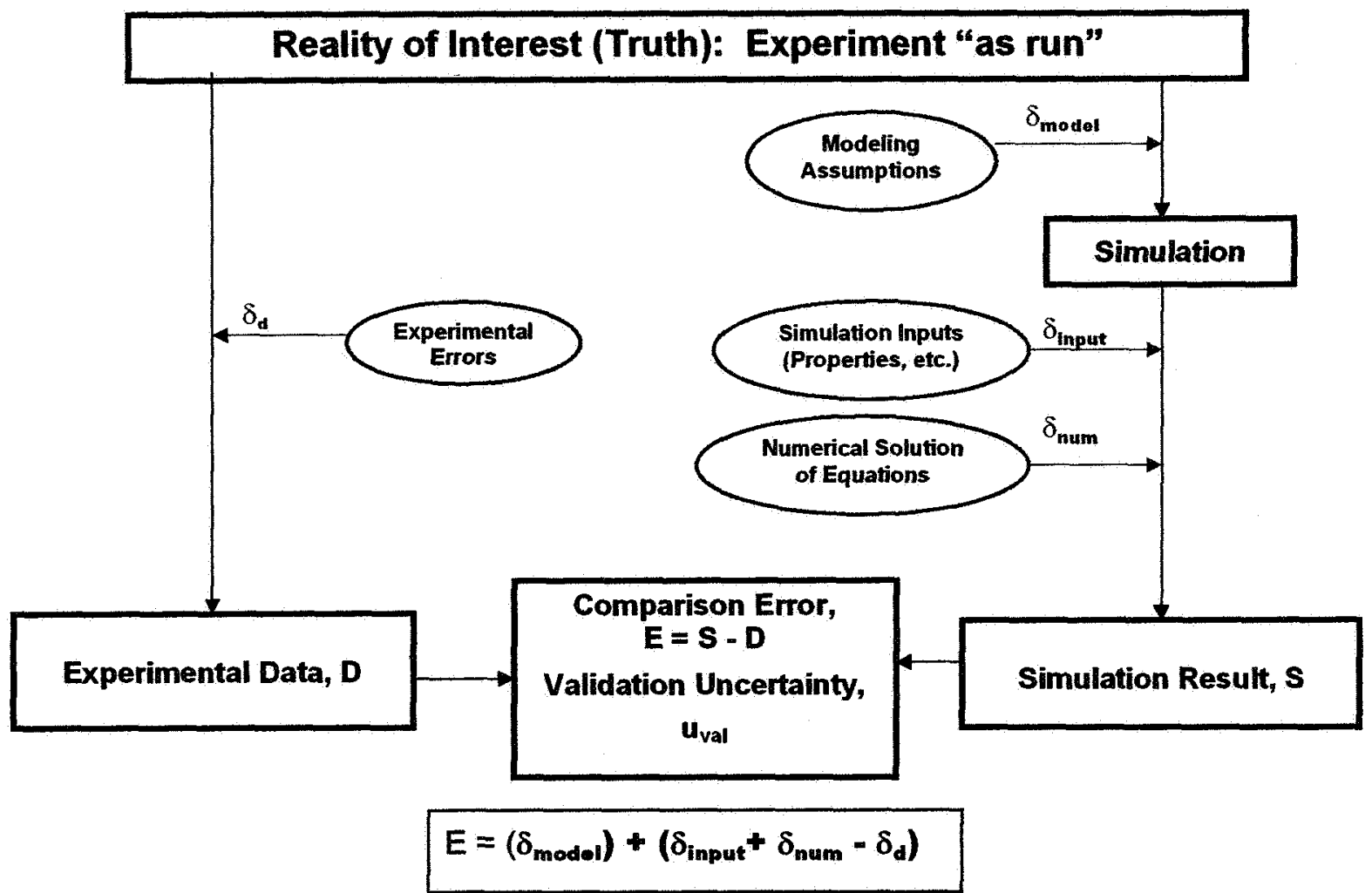

Figure 2. Overview of the validation process with sources of error shown in ovals.

From Eq. (5), the modeling error can be isolated as

$$
\delta_{\text {model }}=\mathrm{E}-\left(\delta_{\text {num }}+\delta_{\text {input }}-\delta_{\mathrm{D}}\right)
$$

Consider each variable in Eq. (6) in turn. There is no general approach for estimating $\delta_{\text {model }}$ prior to comparing $S$ with benchmark experimental data $\mathrm{D}$ - that is an objective of the validation process itself. The sign and magnitude of $E$ are known once $S$ and $D$ are determined; however, the signs and magnitudes of the errors $\delta_{\text {num }}, \delta_{\text {input }}$ and $\delta_{d}$ are unknown, so uncertainties must be estimated. In Ref. 3, a validation uncertainty $u_{\mathrm{val}}$ was defined such that $u_{\mathrm{val}}$ is an estimate of the standard deviation of the parent population of the error that results from the combination of errors $\left(\delta_{\text {num }}+\delta_{\text {input }}-\delta_{d}\right)$. Considering Eq. (6), if $E$ is determined and $u_{\text {val }}$ can be estimated, then an interval within which $\delta_{\text {model }}$ falls can be estimated. To make an estimate of $u_{v a l}$, estimates must be made for $u_{\text {num }}, u_{\text {input }}$, and $u_{d}$. The uncertainty $\mathrm{u}_{\mathrm{num}}$, for instance, is a standard uncertainty ${ }^{4}$ that corresponds conceptually to an estimate of the standard deviation $\sigma$ of the parent distribution from which $\delta_{\text {num }}$ is a single realization. As discussed below, there are techniques for estimating $u_{\text {num }}, u_{\text {input }}$, and $u_{d}$.

Code verification and solution verification processes ${ }^{8}$ are used in estimation of $u_{n u m}$. Code verification is the process of determining that a code is mathematically correct, i.e. it can converge to a correct continuum solution as the discretization is refined. Code verification involves error evaluation from a known solution. Solution verification 
is the process of estimating numerical uncertainty for a particular solution of a problem of interest. The solution verification involves error estimation rather than evaluation from a known benchmark solution.

Estimation of $\mathrm{u}_{\text {input }}$, the uncertainty in the solution $\mathrm{S}$ due to the uncertainties in the simulation input parameters, obviously requires estimates of the uncertainties of all of the input parameters. Then $u_{\text {input }}$ is determined by either using an uncertainty propagation approach that requires estimates of simulation solution sensitivity coefficients or by using a direct Monte Carlo simulation approach.

The uncertainty in the experimental result $u_{d}$ is determined using well-accepted techniques ${ }^{4-6}$ developed by the international community over a period of decades. The estimate $u_{d}$ is the uncertainty appropriate for $D$-it includes all effects of averaging, includes all random and systematic uncertainty components, and includes effects of any correlated experimental errors/uncertainties and any other factors that influence $D$ and $u_{d}$.

Once estimates of $u_{n u m}, u_{i n p u t}$, and $u_{d}$ have been made, then $u_{v a l}$ can be obtained by application of the uncertainty propagation equation or by Monte Carlo simulation.

\section{Validation of Wall Heat Flux}

As discussed in Section III, heat flux is determined based on the measured temperature-time history of coaxial thermocouples. The validation process is thus as shown in Figure 3, since heat flux $q$ is determined by postprocessing the measured temperatures using a model. In this case, additional errors $\delta_{\text {model,D, }}, \delta_{\text {input,D}}$, and $\delta_{\text {num,D }}$ (which is probably negligible) must be considered rather than simply $\delta_{\mathrm{D}}$. Approaches to estimating $\mathrm{u}_{\text {model, }}$ are currently under consideration.

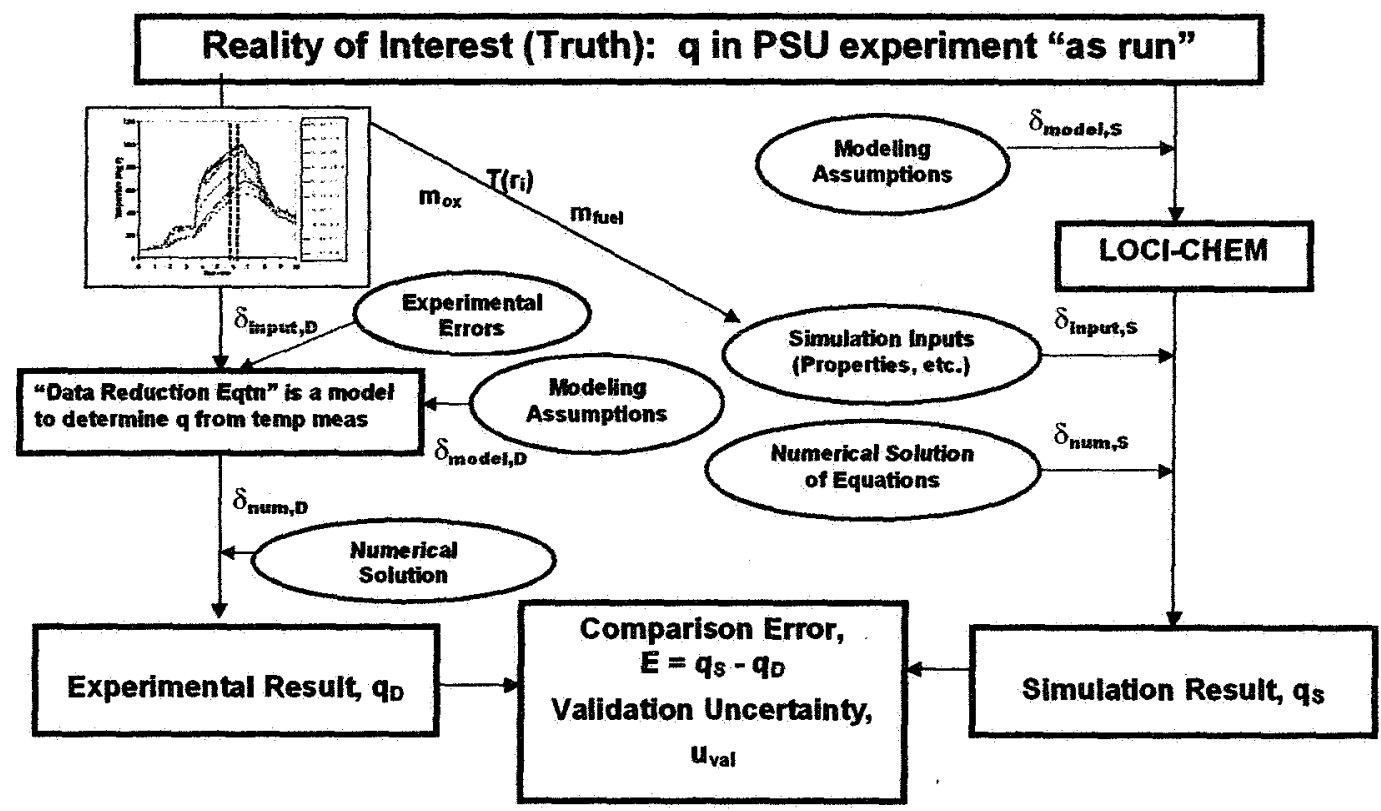

$$
E=\left(\delta_{\text {modol }, \mathrm{s}}-\delta_{\text {madol,D }}\right)+\left(\delta_{\text {imput }, \mathrm{s}}+\delta_{\text {num }, \mathrm{s}}-\delta_{\text {inpur, }, \mathrm{D}}-\delta_{\text {num }, \mathrm{D}}\right)
$$

Figure 3. Overview of the validation process for heat flux with sources of error shown in ovals. 


\section{Experimental Facility and Procedures}

\section{Experimental Plans}

This project is geared towards documenting the chamber wall heat flux characteristics of representative LOX/ $\mathrm{CH}_{4}$ injector elements under rocket conditions. NASA considers the liquid oxygen (LOX)/methane $\left(\mathrm{CH}_{4}\right)$ propellant combination to be a viable candidate for a variety of advanced capabilities areas. Injector technology for this propellant combination has a critical gap in knowledge of detailed wall heat transfer characteristics. In addition, a well defined data base is necessary for validating and anchoring CFD codes that can then be used as design tools for full-scale rocket injectors. The objectives of the project are as follows. The detailed wall heat flux characteristics of three $\mathrm{LOX} / \mathrm{CH}_{4}$ uni-element injectors at three chamber pressure and three mixture ratio conditions utilizing an existing heavily instrumented $l$-inch diameter rocket chamber will be documented. The existing chamber utilizes an array of coaxial thermocouple instrumentation in a heat sink design for detailed wall heat flux measurements. This chamber has recently been utilized to obtain similar detailed wall heat flux characteristics for various LOX/GH $/ \mathrm{GH}_{2}$ injector configurations. A summary of the Cryogenic Combustion Laboratory (CCL) at The Penn State University where these experiments will be conducted is presented first. This summary is followed by a description of the rocket chamber and injector configurations that will be tested under this program.

\section{Facility Description}

The CCL is a unique facility where researchers conduct work on representative rocket engine flow fields. The laboratory was designed based on a similar test cell at NASA Lewis Research Center (now the NASA Glenn Research Center at Lewis Field). The CCL, a remotely controlled laboratory, features a control room, diagnostic room and the test cell. The test cell, where the combustion experiment is housed, is isolated from the control and diagnostic rooms with reinforced concrete walls. For experimentation, the test cell's garage door is fully opened and the ventilation turned on to prevent the possible buildup of combustible materials. The diagnostic room located adjacent to the test cell is utilized for situating all the laser-based diagnostics. Optical ports between the diagnostics room and the test cell provide access into the test cell. The control room houses the computer control system that is used for timing the rocket firing. Video cameras with pan features enable remote visualizations of the test room. The operation of the entire system is designed with two levels of safety.

The CCL was initially operable for gaseous oxygen/hydrogen propellants. Liquid oxygen capability was initiated within a year of the laboratory's operation. Liquid hydrocarbon capability was brought on-line three years later. Finally airflow capability was brought on-line in early 1997. The propellant flowrate capabilities are tabulated Table 1. A relatively recent summary of research conducted at this facility can be found in Ref. 9 .

\section{$\underline{\text { Rocket Assembly }}$}

The wall heat transfer experiments will be conducted using an existing instrumented 1-inch diameter rocket chamber. A schematic of the integrated rocket chamber is shown in Fig. 4. The rocket chamber is modular and can be easily configured to accommodate changes in chamber length or hardware configurations, such as sensor placement or injector design. The chamber sections are held together with a hydraulic jack that allows for easy assembly and arrangement of the various sections. The rocket chamber is a heat sink design made of oxygen-free high conductivity (OFHC) copper. The internal and external diameters of the chamber are $1.0 \mathrm{in}$. and $6.0 \mathrm{in}$., respectively. Chamber length can be varied by inserting or removing chamber sections. For the $\mathrm{LOX} / \mathrm{CH}_{4}$ experiments, the rocket chamber length will be $14.0 \mathrm{in}$. from the injector face to the start of nozzle convergence The design allows for operational pressures of up to 1400 psia, and a water cooled nozzle allows for $\mathrm{LOX} / \mathrm{GH}_{2}$ operation at near stoichiometric conditions. The design of the water cooled nozzle allows for different diameter nozzles to be interchanged, thus providing the capability for changing the main chamber pressure for a given total propellant mass flowrate. The main chamber flow is ignited using a $\mathrm{GO}_{2} / \mathrm{GH}_{2}$ torch igniter (not shown in Fig. 4). 

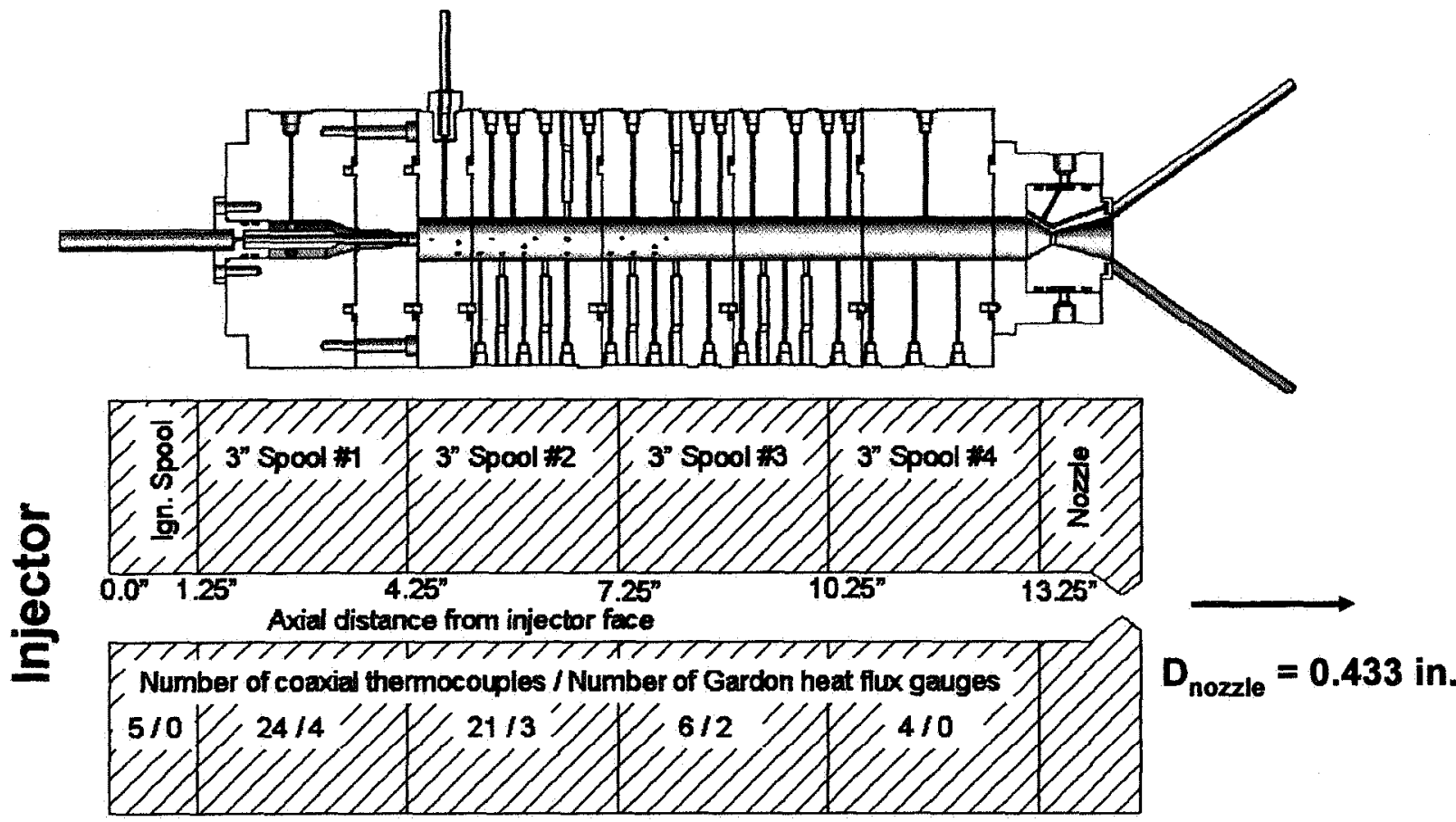

Figure 4. Schematic of the rocket chamber.

Table 1. Flowrate capabilities of CCL.

\begin{tabular}{ll}
\hline Propellant & Maximum Flowrate $(\mathrm{lbm} / \mathrm{s})$ \\
\hline Gaseous Oxygen $\left(\mathrm{GO}_{2}\right)$ & 1 \\
Gaseous Hydrogen $\left(\mathrm{GH}_{2}\right)$ & 0.25 \\
Liquid Oxygen (LOX) & 1 \\
Liquid Hydrocarbon & 0.5 \\
Air & 5 (can be upgraded to 16$)$ \\
\hline
\end{tabular}

The main chamber is instrumented with coaxial thermocouples supplied (and mounted) by MEDTHERM Corporation. Each coaxial thermocouple has a diameter of 0.1 in. with a smaller sensing area. The coaxial thermocouple has two Type-T thermocouples located at the tip and at a recessed location nominally 0.25 in. from the tip. The coaxial thermocouples were press fit into the main chamber wall and the tip was contoured to match the curvature of the chamber. The coaxial thermocouple provides temperature measurements at the two locations, i.e. tip and recessed locations. The wall heat flux can then be evaluated using the appropriate heat flux equation. The chamber is also instrumented with a small number of Gardon type heat flux gauges. These gauges are used for a quick check of the wall heat flux levels during the course of the experiments.

The instrumented main chamber has five sections as shown in Fig. 4. The first section is a $1.25 \mathrm{in}$. long spool termed the "igniter spool". The $\mathrm{GO}_{2} / \mathrm{GH}_{2}$ torch used for igniting the main propellants is mounted on this section. The remaining four spool pieces are each $3.0 \mathrm{in}$. long. The number of coaxial thermocouples and Gardon type heat flux gauges on each of these five spool sections are noted in Fig. 4. For the rocket configuration shown in Fig. 4, there are a total of 60 coaxial thermocouples and 9 Gardon type heat flux gauges available for wall heat flux measurements, with the majority of instrumentation located within the first $7.0 \mathrm{in}$. from the injector face.

Each coaxial thermocouple provides a transient temperature measurement at the hot wall and at a point $0.25 \mathrm{in}$. back from the wall. Since both these temperatures increase with time in a heat-sink rocket chamber, the transient heat equation in cylindrical coordinates needs to be solved to evaluate the wall heat flux. A multi-node discretized procedure will be employed to evaluate the wall heat flux using the appropriate OFHC copper values for the thermal conductivity, $k$, specific heat, $C_{p}$, and density, $\rho$. Note that analyses of previous experiments conducted 

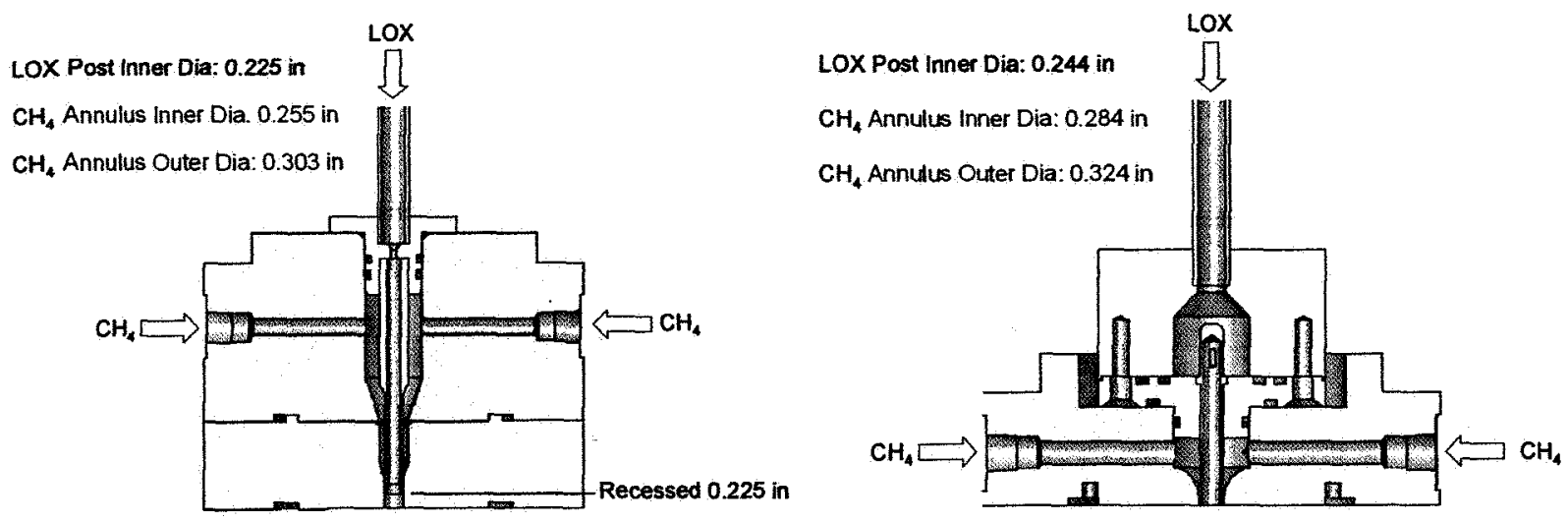

(a) Injector 1 - Shear coaxial injector (A)

(b) Injector 2 - Swirl coaxial injector

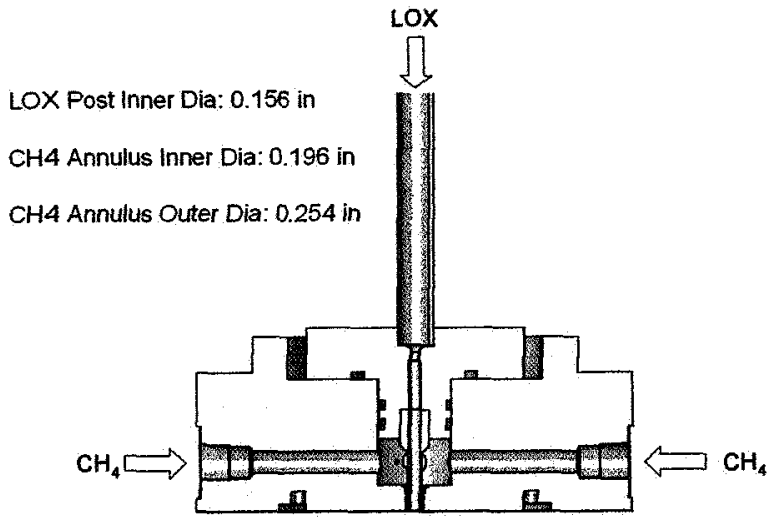

\begin{tabular}{lccc}
\hline & Injector 1 & Injector 2 & Injector 3 \\
\hline LOX Mass Flow rate (Ib/s) & 0.700 & 0.700 & 0.700 \\
CH4 Mass Flow rate (lb/s) & 0.233 & 0.233 & 0.233 \\
LOX Velocity (ft/s) & 39.5 & 87.6 & 82.0 \\
CH, Velocity (ft/s) & 423.0 & 461.0 & 433.3 \\
Injector AP - LOX (psid) & 386.9 & 123.8 & 150.0 \\
Injector $\Delta P$ - CH4 (psid) & 66.2 & 66.2 & 69.7 \\
Velocity Ratio (F/O) & 10.70 & 5.26 & 5.28 \\
Momentum Ratio (F/O) & 3.57 & 1.75 & 1.76 \\
Mom. Flux Ratio (F/O) & 6.74 & 1.63 & 1.64 \\
\hline
\end{tabular}

(c) Injector 3 - Shear coaxial injector (B) (d) Target flow conditions at $P_{c}=1200 \mathrm{psia} ; \mathrm{O} / \mathrm{F}=3.0$

Fig. 4. Injector configurations (a-c) and target flow conditions (d).

in a similar rocket chamber for $\mathrm{GO}_{2} / \mathrm{GH}_{2}$ propellant injectors indicate that the results obtained using this procedure is nominally at most $6 \%$ higher than that obtained using a quasi steady state assumption [10].

\section{Injector Configurations}

Detailed wall heat flux measurements will be made for three $\mathrm{LOX} / \mathrm{CH}_{4}$ injectors under this program. All three injectors have been designed and fabricated for a design point of chamber pressure of $1200 \mathrm{psia}, \mathrm{O} / \mathrm{F}$ of 3.0 and LOX flowrate of $0.7 \mathrm{lbm} / \mathrm{s}$. The three injectors that will be investigated are (1) a baseline shear coaxial injector, (2) a swirl coaxial injector, and (3) a different version of a shear coaxial injector. Schematics of these three unielement injectors (viz. injectors 1-3) are included in Fig. 5 along with a summary of the flow conditions at the aforementioned design point. In contrasting the two shear coaxial injectors (i.e. injectors 1 and 3), atomization, and therefore mixing and combustion will be more rapid for injector 1 since the design momentum flux ratio between the fuel and oxidizer streams is higher by a factor of four. The measurements of wall heat flux will therefore be different between these two injectors. On the other hand, the swirl coaxial injector, viz. injector 3 , will exhibit more near injector face combustion due the enhanced atomization realized through swirling the central LOX flow (calculated swirl cone angle is about $70^{\circ}$ ). These three injector designs were chosen because they have direct engineering importance, and are expected to exhibit different heat transfer characteristics. The test matrix plan for all three injector configurations includes testing at pressures from nominally 1200 psia down to 300 psia, and at mixture ratios of $2.5,3.0$ and 3.25 . All experiments will be conducted utilizing the same nozzle, and therefore propellant flowrates at lower target chamber pressures will be scaled proportionately.

Since one of the goals of these experiments is to obtain benchmark measurements for CFD code verification and validation, it is necessary to investigate injector designs where the wall heat flux profiles differ significantly. 
Clearly, a CFD code needs to correctly predict wall heat flux characteristics for a wide range of flow and heat load conditions, and the current experimental program aims to provide such measurements.

\section{The Loci-CHEM Computer Code}

Loci-CHEM is a finite-volume flow solver for generalized grids developed at Mississippi State University in part via NASA and NSF funded efforts. CHEM uses high resolution approximate Riemann solvers to solve finite-rate chemically reacting viscous turbulent flows. Preconditioning ${ }^{11}$ is available for low Mach number applications. Details of the numerical formulation are presented in the CHEM user guide ${ }^{12}$. Various chemical reaction mechanisms are available, the model used in this study for hydrogen/oxygen is a 6 species 28 reaction model ${ }^{13}$ as shown in Table 2. Thermodynamic properties are provided via the NASA CEC property curve fits ${ }^{14}$. Several turbulence models are available; the Mentor Shear Stress Transport (SST) k-omega model was used in the current study. Loci-CHEM is comprised entirely of $\mathrm{C}$ and $\mathrm{C}++$ code and is supported on all popular UNIX variants and compilers. Parallelism is supplied by the Loci ${ }^{15}$ framework which exploits multi-threaded and MPI libraries to provide parallel capability.

Table 2. The 6 species hydrogen oxygen reaction model. Units are $m k s . k_{f}=A T^{n} e^{(-E / R T)}, k_{r}$ determined from $\mathrm{Kc}$.

\begin{tabular}{|c|l|c|c|c|}
\hline Step & \multicolumn{1}{|c|}{ Reaction } & A & n & E/R (K) \\
\hline \multicolumn{5}{|c|}{ Non M-body Reactions } \\
\hline 1 & H2O + O <->2 OH & $5.8 \times 10^{10}$ & 0 & 9059 \\
\hline 2 & $\mathrm{H} 2 \mathrm{O}+\mathrm{H}<->\mathrm{OH}+\mathrm{H} 2$ & $8.4 \times 10^{10}$ & 0 & 10116 \\
\hline 3 & $\mathrm{O} 2+\mathrm{H}<->\mathrm{OH}+\mathrm{O}$ & $2.2 \times 10^{11}$ & 0 & 8455 \\
\hline 4 & $\mathrm{H} 2+\mathrm{O}<->\mathrm{OH}+\mathrm{H}$ & $7.5 \times 10^{10}$ & 0 & 5586 \\
\hline \multicolumn{5}{|c|}{ M-body Reactions } \\
\hline 5 & $\mathrm{H} 2+\mathrm{M}<->2 \mathrm{H}+\mathrm{M}$ & $5.5 \times 10^{15}$ & -1 & 51987 \\
\hline 6 & $\mathrm{O} 2+\mathrm{M}<->2 \mathrm{O}+\mathrm{M}$ & $7.2 \times 10^{15}$ & -1 & 59340 \\
\hline 7 & $\mathrm{H} 2 \mathrm{O}+\mathrm{M}<->\mathrm{OH}+\mathrm{H}+\mathrm{M}$ & $5.2 \times 10^{18}$ & -1.5 & 59386 \\
\hline 8 & $\mathrm{OH}+\mathrm{M}<->\mathrm{O}+\mathrm{H}+\mathrm{M}$ & $8.5 \times 10^{15}$ & -1 & 50830 \\
\hline
\end{tabular}

\section{Acknowledgments}

This work has been funded, either in whole or in part, through the NASA Constellation University Institutes Project. The authors express their appreciation for the supportive efforts of Claudia Meyer and Jeff Rybak of Glenn Research Center and Kevin Tucker and Jeff West of Marshall Space Flight Center.

\section{References}

1. Tucker, P. and Rybak, J., "The NASA Constellation Universities Institute Project: Thrust Chamber Assembly Virtual Institute," AIAA Paper No. 2006-4524, 42 ${ }^{\text {nd }}$ Joint Propulsion Conference, Sacramento, CA, July 2006.

2. Oberkampf, W. L. and Trucano, T. G., "Verification and Validation in Computational Fluid Dynamics," Progress in Aerospace Sciences, Vol. 38, 2002.

3. Coleman, H.W. and Stern, F., "Uncertainties in CFD Code Validation," ASME J. Fluids Engineering, Vol. 119, pp. 795803, Dec. 1997.

4. Guide to the Expression of Uncertainty in Measurement, (corrected and reprinted, 1995), International Organization for Standardization, Geneva, Switzerland, 1995.

5. ASME PTC 19.1-2005, Test Uncertainty.

6. Coleman, H.W. and Steele, W.G., Experimentation and Uncertainty Analysis for Engineers, $2^{\text {nd }}$ Edition, John Wiley \& Sons, New York, 1999.

7. International Vocabulary of Basic and General Terms in Metrology, $2^{\text {nd }}$ Edition, International Organization for Standardization, Geneva, Switzerland, 1993.

8. Roache, P. J., Verification and Validation in Computational Science and Engineering, Hermosa, 1998. 
9. Santoro, R. J., Pal, S., Woodward, R., and Schaaf, L., "Rocket Testing at University Facilities," AIAA Paper No. 20010748 , January 2001.

10. Marshall, W. M., Pal, S., Woodward, R. D., and Santoro, R. J., "Benchmark Wall Heat Flux Data for a $\mathrm{GO}_{2} / \mathrm{GH}_{2}$ Single Element Combustor," AIAA Paper No. 2005-3572, July 2005.

11. Luke, E. A., Tong, X.-L. and Cinnella, P., "Numerical Simulations of Fluids with a General Equation of State," AIAA Paper No. 12951, 44th Aerospace Sciences Meeting, January 9-12, 2006, Reno, NV

12. Luke, E. A., Tong, X-L., Wu, J., and Cinnella, P. "CHEM 2: A Finite-Rate Viscous Chemistry Solver - The User Guide" MSSU-COE-ERC-04-07, Mississippi State University, September, 2004.

13. Evans, J. S., and Schexnayder, C. J.., AIAA Journal, Vol 18, No 2, January 1980, p 188-193.

14. Gordon, S. and McBride, B. "Computer Program for Calculation of Complex Chemical Equilibrium Compositions, Rocket Performance, Incident and Reflected Shocks and Chapman-Jouguet Detonations", NASA SP 273, 1971.

15. Luke, E. A., "A Rule-Based Specification System for Computational Fluid Dynamics", Ph.D. Dissertation, Mississippi State University, Starkville, MS, 1999. 